\title{
Social determinants of health associated with hemodialysis non-adherence and emergency department utilization: a pilot observational study
}

Kamna S. Balhara ${ }^{1 *}$ (D) Lori Fisher ${ }^{1,2}$, Naya El Hage ${ }^{1,3}$, Rosemarie G. Ramos ${ }^{4}$ and Bernard G. Jaar ${ }^{1,5,6,7}$

\begin{abstract}
Background: Dialysis patients who miss treatments are twice as likely to visit emergency departments (EDs) compared to adherent patients; however, prospective studies assessing ED use after missed treatments are limited. This interdisciplinary pilot study aimed to identify social determinants of health (SDOH) associated with missing hemodialysis (HD) and presenting to the ED, and describe resource utilization associated with such visits.
\end{abstract}

Methods: We conducted a prospective observational study with a convenience sample of patients presenting to the ED after missing HD (cases); patients at local dialysis centers identified as HD-compliant by their nephrologists served as matched controls. Patients were interviewed with validated instruments capturing associated risk factors, including SDOH. ED resource utilization by cases was determined by chart review. Chisquare tests and ANOVA were used to detect statistically significant group differences.

Results: All cases visiting the ED had laboratory and radiographic studies; 40\% needed physician-performed procedures. Mean ED length of stay (LOS) for cases was $17 \mathrm{~h}$; $76 \%$ of patients were admitted with average LOS of 6 days. Comparing 25 cases and 24 controls, we found no difference in economic stability, educational attainment, health literacy, family support, or satisfaction with nephrology care. However, cases were more dependent on public transport for dialysis $(p=0.03)$. Despite comparable comorbidity burdens, cases were more likely to have impaired mobility, physical limitations, and higher severity of pain and depression. $(p<$ 0.05).

Conclusions: ED visits after missed HD resulted in elevated LOS and admission rates. Frequently-cited SDOH such as health literacy did not confer significant risk for missing HD. However, pain, physical limitations, and depression were higher among cases. Community-specific collaborations between EDs and dialysis centers would be valuable in identifying risk factors specific to missed HD and ED use, to develop strategies to improve treatment adherence and reduce unnecessary ED utilization.

Keywords: Social determinants of health, Dialysis, Emergency department, Non-adherence

\footnotetext{
* Correspondence: kamna.balhara@gmail.com

${ }^{1}$ The Johns Hopkins University School of Medicine, Baltimore, MD, USA

Full list of author information is available at the end of the article
}

(C) The Author(s). 2020 Open Access This article is distributed under the terms of the Creative Commons Attribution 4.0 International License (http://creativecommons.org/licenses/by/4.0/), which permits unrestricted use, distribution, and reproduction in any medium, provided you give appropriate credit to the original author(s) and the source, provide a link to the Creative Commons license, and indicate if changes were made. The Creative Commons Public Domain Dedication waiver (http://creativecommons.org/publicdomain/zero/1.0/) applies to the data made available in this article, unless otherwise stated. 


\section{Background}

Almost half of hospital-associated medical care in the United States is delivered in the Emergency Department (ED) [1]. Overall, EDs in the United States treat over 135 million patients annually [2]. With subsequent rising costs and ED overcrowding, there is an increased focus on identifying patients at higher risk of frequent, possibly preventable, visits [3-5]. Such patients include those undergoing dialysis for end-stage renal disease (ESRD) $[3,6]$. Over the past several decades, the number of patients receiving dialysis for ESRD in the United States has increased significantly, from about 56,000 in 1980 to more than 500,000 in 2016 [7]. Consequently, the incidence of ED care for ESRD patients has also increased and is now six to eight times greater than that of the general population, with up to twice the ED length of stay and significantly higher admission rates [8-10]. Among ESRD patients who shorten or miss dialysis treatments, the risk of ED care further doubles and the risk of re-hospitalization quadruples; missed dialysis treatments are associated with all-cause mortality and worse health [11-14].

Despite growing ED utilization by dialysis patients and its attendant cost and morbidity, prospective studies to identify risk factors for ED utilization by dialysis patients who have missed dialysis treatments remain limited. Patients on scheduled maintenance dialysis miss treatments and present to the ED despite established weekly points of contact with the outpatient healthcare system. Access to ambulatory care does not fully explain the risk of ED visits in ambulatory care sensitive conditions; elements such as income, ethnicity, cultural background, and trust with the healthcare system impact ED utilization [15-18]. Similarly, community-level determinants may play a role in dialysis non-adherence and ED utilization [19]. The World Health Organization (WHO), Centers for Disease Control (CDC), and the Healthy People 2020 and 2030 initiatives have all placed an increased focus upon social determinants of health $(\mathrm{SDOH})$, i.e. the conditions in the places where people live, learn, work, and play. SDOH impact patients' behavioral choices and are associated with clinical outcomes in ESRD patients [20-23]. Unmet SDOH in the ESRD patient may predict non-adherence to dialysis treatment and the incidence of preventable ED visits or hospitalizations. However, SDOH have not received sufficient attention in ESRD patients, and there is very limited prospective data on $\mathrm{SDOH}$ and their impact on dialysis non-adherence and ED utilization [20]. The urban ED, which serves as a "window into the community" and a social safety net, is poised to address the aforementioned research gaps [24, 25]. Therefore, this pilot study seeks to identify the specific medical factors and $\mathrm{SDOH}$ associated with missing hemodialysis (HD) and subsequent ED utilization, and to describe the resultant resource use upon presenting to the ED.

\section{Methods \\ Study design, setting, and population}

This pilot interview-based study used a prospective observational design with a control group. Cases (patients who had missed at least one HD session prior to ED visit) were recruited in the ED of a large academic center (site 1). Controls (patients deemed adherent by their nephrologist) were recruited from a population of those regularly attending a large local outpatient HD clinic (site 2).

Both sites are located in the same large urban city and serve communities in the same urban setting. Site 1 is an ED at an academic, tertiary care center with approximately 70,000 visits per year and a $22 \%$ admission rate. Site 2 is a large outpatient HD center in the same city with nearly 300 chronic outpatient HD patients. Sessions are offered daily, with the exception of Sundays. The study was approved by the institutional review boards at both institutions.

Patients were eligible to participate as cases if they had missed at least one HD session prior to ED visit at site 1, were over age 18, and spoke English. Patients who had already participated, were deemed critically ill by ED clinicians, or were unable to consent were excluded.

After chart review and documentation review by their treating nephrologists, patients at site 2 who had missed 0 dialysis sessions in the year preceding recruitment were identified as potential controls. Controls were matched to cases to ensure a similar distribution of gender, age, diagnosis of diabetes as a comorbidity and years on dialysis. Controls were eligible for inclusion if they were aged over 18 and spoke English.

\section{Study protocol and outcome measures}

Trained research staff at site 1 prospectively identified cases, i.e. patients who may have missed HD, by reviewing patient charts of current visits in the electronic medical record (EMR) and obtained the treating clinician's permission prior to approaching patients. When research staff was not on-site, ED clinicians notified research staff of potentially eligible patients after obtaining patient permission to be contacted. Research staff then contacted potentially eligible patients either while in the ED, while admitted to the hospital, or over the phone after hospital discharge if the patient became too ill for interview completion during the ED visit or if the patient left the ED prior to interview completion. Consenting participants completed interviews either in-person or over the phone. Written consent was obtained from participants recruited in-person, and verbal consent using a standardized script was obtained from 
patients recruited over the phone. Both consent strategies were approved by both institutional review boards.

Research staff approached eligible controls at site 2 for recruitment during their scheduled regular outpatient HD sessions and participants providing written consent completed interviews in-person.

Both cases and controls completed the same interview with research staff, with the exception of additional questions for cases regarding reasons for missed HD and number of missed HD sessions prior to ED visit. Comorbidities, degree of disability, and depression were assessed using instruments validated in dialysis patients (the Charlson comorbidity index, Kidney Disease Quality of Life Instrument [KD-QOL], and Patient Health Questionnaire-9 [PHQ-9], respectively) [26-28]. Pain levels in preceding weeks were documented, along with alcohol and illicit substance use.

The interview subsequently gathered data on various categories of SDOH. Key domains aligned with the Healthy People 2020 Approach to SDOH categorizations were 1) economic stability, 2) neighborhood and built environment, 3) education, 4) healthcare access, and 5) social and community context [29]. Our measures of economic stability included employment status and the Distressed Communities Index (DCI) [30]. The DCI combines seven metrics (high school diploma, housing vacancy rate, unemployment, poverty rate, median income ratio, change in employment, change in business establishments) based upon zip-code to generate a measure of community economic well-being. Neighborhood and built environment were examined with the $\mathrm{DCI}$, mode of transportation to $\mathrm{HD}$, and distance to HD center. Education was assessed by highest level of formal education achieved. Health care access was assessed via health literacy with a brief questionnaire (Rapid Estimate of Adult Literacy in Medicine Short Form or REALM-SF), which has been validated in the dialysis population [31, 32]. Social and community contexts were captured by determining level of family support, availability of back-up plans for missed HD, and satisfaction with care (with the Choices for Healthy Outcomes in Caring for End-Stage Renal Disease Satisfaction Questionnaire) as a surrogate for attitude and trust towards the medical system [33,34].

In both populations, EMR chart reviews were used to verify patient comorbidities. For cases, data on patient disposition, length of stay, and resource use were gathered from EMR chart review. Chart review was conducted by trained abstractors using a standardized abstraction form. A sample of charts (20\% from each group) was reviewed by a study author (KB) to ensure accuracy.

\section{Data analysis}

Data were collected and managed using REDCap electronic data capture tools hosted at Johns Hopkins
University [35]. All data were checked for consistency and outliers were examined. Two sample tests of proportions and chi-square analysis or test of medians when appropriate were used to identify significant $(p<0.05)$ differences between cases and controls. STATA 12.0 (Stata Corp, College Station, TX) was used for analysis.

\section{Results}

Thirty-two eligible cases were identified; four declined to participate and study team members were not able to reach three patients by phone after their hospital visit. Twenty-eight controls were identified; three declined to participate and one was hospitalized during the recruitment period for a non-hemodialysis related cause. In sum, 25 cases and 24 controls were successfully recruited and completed the study.

In our recruitment process, we controlled for gender, age, diabetic status, and years on dialysis, and, accordingly, groups did not differ significantly in these factors. $(p>0.05)$ (Table 1) Most participants were AfricanAmerican and had been on HD for less than 5 years. $44.9 \%$ were female; $32.7 \%$ were diabetic.

\section{Characteristics of ED visits by patients who missed HD}

Among cases, the most common reasons for missing HD included feeling unwell or having issues with transportation. Notably, three out of seven patients reporting transportation issues had difficulties related to the state mobility program. (Table 2) Fourteen cases (56\%) had missed one session of HD prior to ED presentation, whereas five (20\%) had missed two sessions and six (24\%) had missed three or more sessions. The most frequent complaint on presentation was shortness of breath (six patients, 24\%) and six patients $(24 \%)$ were acuity level 2 on the Emergency Severity Index (ESI) scale, whereas the remainder were level 3 (ESI level 1 represents highest acuity, with 5 being lowest) [36]. Most patients arrived by private vehicle $(12,48 \%)$ or ambulance (9, 36\%).

While in the ED, all patients had laboratory studies drawn, received at least one radiographic study, and had at least one specialty consulting service involved in their care. $52 \%$ required intravenous medications, and 32\% required intravenous access placed via ultrasound guidance by an emergency department physician. $76 \%$ of patients subsequently had an in-patient stay; only $24 \%$ of patients were directly discharged from the ED with a median length of stay of $14 \mathrm{~h}$. (Table 3) Almost half of admitted patients were placed in monitored units (48\%), while $16 \%$ required an intensive care unit admission at some point during their inpatient stay. Median inpatient length of stay was up to 6 days. 
Table 1 Baseline patient characteristics, comorbidities, mobility, pain, depression, and substance use

\begin{tabular}{|c|c|c|c|}
\hline Characteristic & Cases & Controls & $P$-value \\
\hline Female patients - n (\%) & $11(44.0)$ & $11(45.8)$ & 0.897 \\
\hline Age - mean years (SD) & $53.68(12.77)$ & $55.42(10.64)$ & 0.7564 \\
\hline Hemodialysis vintage - n (\%) & & & 0.639 \\
\hline$<1$ year & $4(16.0)$ & $5(20.8)$ & \\
\hline $1-5$ years & $15(60.0)$ & $10(41.7)$ & \\
\hline$>5-10$ years & $4(16.0)$ & $6(25.0)$ & \\
\hline$>10$ years & $2(8.0)$ & $3(12.5)$ & \\
\hline Ethnicity - n (\%) & & & 0.972 \\
\hline African-American & $24(96.0)$ & $23(95.8)$ & \\
\hline Caucasian & $1(4.0)$ & $1(4.2)$ & \\
\hline \multicolumn{4}{|l|}{ Comorbidities - n (\%) } \\
\hline Diabetes & $8(36.0)$ & $8(33.3)$ & 0.844 \\
\hline Hypertension & $18(72.0)$ & $24(100.0)$ & 0.008 \\
\hline Coronary artery disease & $7(28.0)$ & $5(20.1)$ & 0.523 \\
\hline Congestive heart failure & $7(28.0)$ & $8(33.3)$ & 0.690 \\
\hline Charlson Comorbidity Index - median (IQR) ${ }^{b}$ & $6(4-8)$ & $5(3.5-7)$ & 0.23 \\
\hline \multicolumn{4}{|l|}{ Degree of mobility - n (\%) } \\
\hline Fully mobile without assistance & $8(32)$ & $20(83)$ & $<0.001$ \\
\hline Reliant on cane & $11(44)$ & $3(12.5)$ & 0.015 \\
\hline Reliant on walker & $8(32)$ & $1(4.2)$ & 0.012 \\
\hline Reliant on wheelchair & $2(8)$ & $0(0)$ & 0.157 \\
\hline Health limitation score (KD-QOL) median (IQR) ${ }^{\mathrm{a}, \mathrm{b}}$ & $35(10-85)$ & $60(45-95)$ & 0.02 \\
\hline Degree of bodily pain in preceding weeks - $\mathrm{n}(\%)$ & & & $<0.001$ \\
\hline None & $3(12)$ & $10(41.7)$ & \\
\hline Very mild/mild & $3(12)$ & $11(45.8)$ & \\
\hline Moderate & $3(12)$ & $1(4.2)$ & \\
\hline Severe/very severe & $16(64)$ & $2(8.3)$ & \\
\hline PHQ-9 Depression score - n (\%) & & & 0.016 \\
\hline None & $7(28)$ & $17(70.8)$ & \\
\hline Mild & $7(28)$ & $5(20.8)$ & \\
\hline Moderate & $4(16)$ & $2(8.3)$ & \\
\hline Moderately Severe & $5(20)$ & $0(0)$ & \\
\hline Severe & $2(8)$ & $0(0)$ & \\
\hline \multicolumn{4}{|l|}{ Alcohol and substance use } \\
\hline Ever use illicit drugs & $12(48)$ & $7(29.2)$ & 0.176 \\
\hline Ever use alcohol & $14(56)$ & $7(29.2)$ & 0.06 \\
\hline In methadone/suboxone program & $3(12)$ & $0(0)$ & 0.08 \\
\hline Currently use alcohol & $1(4)$ & $2(8.3)$ & 0.527 \\
\hline Currently use illicit drugs & $5(20.8)$ & $1(4.2)$ & 0.081 \\
\hline
\end{tabular}

alower scores signify greater limitations

${ }^{\mathrm{b}} 25-75 \%$ interquartile range

Medical factors associated with ED visits after missing dialysis

No significant differences were noted between groups in comorbidity burden as assessed by the Charlson
Comorbidity Index $(p=0.23)$. (Table 1$)$ However, cases were significantly less likely to be fully mobile $(p<$ 0.001 ), had greater reliance on mobility adjuncts $(p=$ $0.015,0.012$ ), and had poorer scores on the healthcare 
Table 2 Reasons provided for missing dialysis

\begin{tabular}{ll}
\hline Reason for missing dialysis & $\mathrm{n}(\%)$ \\
\hline Not feeling well & $6(21)$ \\
Transportation issue & $7(24)$ \\
Bad weather & $1(4)$ \\
Social or family obligations & $4(16)$ \\
Systems issue (insurance, lack of chair at center, etc) & $6(24)$ \\
Vascular access problem & $2(8)$ \\
Physical limitations & $3(12)$ \\
\hline
\end{tabular}

limitations scale as measured by the KD-QOL $(p=0.02)$. Cases also had significantly higher levels of pain, with the majority (64\%) expressing severe or very severe bodily pain in the preceding 4 weeks $(p<0.001)$. Most controls were scored as having no depression on PHQ-9 screening, whereas cases had significantly higher rates of moderate $(16 \%)$, moderately severe $(20 \%)$, or severe depression $(8 \%)(p=0.016)$. No significant differences in patterns of alcohol or drug use were found between groups $(p>0.05)$; however, current participation in methadone or suboxone programs among cases trended towards significance $(p=0.08)$ (Table 1$)$.

\section{Social determinants of health associated with ED visits after missing dialysis}

Groups did not differ significantly in economic stability as measured by employment status and the Distressed Communities Index (DCI) $(p=0.749)$. (Table 4) Most patients were receiving disability or retired, with no significant difference in distribution between groups ( $p=$ 0.418). $44.9 \%$ of all subjects lived in distressed communities, with another $36.7 \%$ living in at-risk communities. There was no difference noted in overall distribution between groups. Cases had a larger proportion living in distressed communities compared to a larger proportion of controls in the at-risk tier, but this difference was not statistically significant. Moreover, these tiers are adjacent in ranking in the DCI.

Controls were significantly more likely to drive themselves when going to HD $(p=0.002)$, whereas cases were more likely to rely on public transportation $(p=0.024)$. However, there was no significant difference between groups in distance traveled to their outpatient HD center from home $(p=0.09)$. We did note a larger proportion of cases living more than 5 miles from their outpatient HD center, but this difference was not statistically significant. Our sample size did not permit differentiation by mode of transport when examining impact of distance.

There was no significant difference in maximum educational attainment between groups $(p=0.872)$, and groups did not differ in degree of health literacy as measured by REALM-SF ( $p=0.831)$. (Table 4 ) Health literacy was assessed for a convenience sample of cases, since six interviews were conducted over the phone. Respondents were also asked about patterns of ED use. Cases were more likely than controls to report visiting the ED multiple times a year for any medical problem. $(p=0.02)$.

The majority of respondents $(70.8 \%$ of controls and $64.0 \%$ of cases) reported that their family was very involved in their medical care, and the majority reported that their families were somewhat or very supportive of their medical care (95.9\% of controls and 92\% of cases), with no significant difference between groups. Most patients reported having a reliable back-up plan if unable to get to $\mathrm{HD}$, with no significant difference between groups (63.2\% of cases and $62.5 \%$ of controls). Overall, groups did not differ significantly in how frequently they assigned an "excellent" rating to their nephrologists, outpatient HD center staff, and HD center as a whole. $91.7 \%$ of cases and $75.1 \%$ of controls would probably or

Table 3 Disposition of cases presenting to the emergency department; LOS = length of stay

\begin{tabular}{|c|c|c|}
\hline Disposition & n (\%) & $\begin{array}{l}\text { Total LOS in hours - } \\
\text { Median ( } 25-75 \% \text { IQR) }\end{array}$ \\
\hline Discharged from ED & $6(24)$ & $14(12-22)$ \\
\hline Observation status in ED & $1(4)$ & 12.0 \\
\hline \multicolumn{3}{|l|}{ Inpatient } \\
\hline Observation & $4(16)$ & $29(29-33.5)$ \\
\hline Full admission as inpatient & $14(56)$ & $142.5(85-221)$ \\
\hline \multicolumn{3}{|l|}{ If inpatient, type of unit ${ }^{a}$} \\
\hline Non-monitored & $5(20)$ & $144(72-92)$ \\
\hline Monitored & $12(48)$ & $84(60-156)$ \\
\hline Intermediate care unit & $1(4)$ & 72.0 \\
\hline Intensive care unit & $4(16)$ & $48(24-84)$ \\
\hline
\end{tabular}

${ }^{a}$ some patients spent time in more than one unit (level of care upgraded or transferred) 
Table 4 Economic stability and neighborhood, education, and healthcare access

\begin{tabular}{|c|c|c|c|}
\hline Characteristic & Cases & Controls & $P$-value \\
\hline Current employment status - n (\%) & & & 0.418 \\
\hline Full-time & $0(0.0)$ & $2(8.3)$ & \\
\hline Part-time & $1(4.0)$ & $2(8.3)$ & \\
\hline Unemployed & $2(8.0)$ & $2(8.3)$ & \\
\hline On-disability & $15(60.0)$ & $15(62.5)$ & \\
\hline Retired & $7(28.0)$ & $3(12.5)$ & \\
\hline Distressed communities index - $\mathrm{n}(\%)$ & & & 0.749 \\
\hline Prosperous & $2(8.0)$ & $1(4.2)$ & \\
\hline Comfortable & $2(8.0)$ & $2(8.3)$ & \\
\hline Mid-tier & $1(4.0)$ & $1(4.2)$ & \\
\hline At-risk & $7(26.9)$ & $11(45.8)$ & \\
\hline Distressed & $13(52)$ & $9(37.5)$ & \\
\hline \multicolumn{4}{|l|}{ Mode of transport to dialysis - $\mathrm{n}(\%)$} \\
\hline Drive self & $4(16)$ & $14(58.3)$ & 0.002 \\
\hline Public transportation & $7(28)$ & $1(4.2)$ & 0.024 \\
\hline State mobility service & $9(36)$ & $3(12.5)$ & 0.056 \\
\hline Walk & $2(8)$ & $1(4.2)$ & 0.576 \\
\hline Rides from family/friends & $6(24)$ & $1(4.2)$ & 0.047 \\
\hline Other & $2(8)$ & $4(16.7)$ & 0.355 \\
\hline Distance from dialysis center - n (\%) & & & 0.09 \\
\hline 1 mile or less & $4(17.4)$ & $6(25.0)$ & \\
\hline $1-5$ miles & $10(43.5)$ & $15(62.5)$ & \\
\hline$>5$ miles & $9(39.1)$ & $3(12.5)$ & \\
\hline Unsure & $2(8.0)$ & $0(0)$ & \\
\hline Educational attainment - n (\%) & & & 0.872 \\
\hline Some high school & $7(28.0)$ & $5(20.8)$ & \\
\hline Completed high school/obtained GED & $7(28.0)$ & $7(29.2)$ & \\
\hline Some college & $7(28.0)$ & $9(37.5)$ & \\
\hline College degree or postgraduate degree & $4(16.0)$ & $3(12.5)$ & \\
\hline Health literacy (REALM-SF) - n (\%) & & & 0.831 \\
\hline 3rd grade and below & $1(5.6)$ & $2(8.3)$ & \\
\hline 4th-6th grade & $3(16.7)$ & $3(12.5)$ & \\
\hline 7th-8th grade & $4(22.2)$ & $8(33.3)$ & \\
\hline High school & $10(55.6)$ & $11(45.8)$ & \\
\hline
\end{tabular}

definitely recommend their dialysis center to others. $(p=0.099)$.

\section{Discussion}

This prospective pilot study examines dialysis nonadherence and subsequent ED utilization through the lens of social determinants of health (SDOH). Nonadherent patients presenting to the ED had significantly higher levels of pain, depression, and limitations in mobility, despite comparable comorbidity burdens, and were more likely to rely on public transport, with economic stability and built environment similar to that of controls. Our findings suggest heavy ED resource use by such patients with higher-than-average admission rates, and likely underestimate resource consumption, as critically ill non-adherent patients were not included.

To date, there are very limited studies which prospectively identify risk factors predicting ED visits among patients who miss dialysis treatments. Existing literature is primarily retrospective, regional registry-based, and focused on all-comers, without specific consideration of the non-adherent dialysis patient $[8,9,19,37]$. The limited number of studies examining HD non-adherence have been post-hoc analyses and have not specifically identified populations at risk of ED utilization after nonadherence $[11,38]$. There also remains a paucity of studies examining the relationship of SDOH with dialysis adherence or directly engaging on patients on reasons for missed treatment sessions. Retrospective studies are limited in their ability to capture key $\mathrm{SDOH}$, such as attitudes towards medical care, degree of community engagement, or social support. Furthermore, registrybased studies lack the granularity necessary to examining relevant $\mathrm{SDOH}$ within local contexts.

To address the aforementioned evidence gaps, we prospectively examined risk factors predicting ED visits among patients who had been non-adherent to dialysis. Despite a comparable comorbidity burden, non-adherent patients in our study had higher rates of physical limitations and limited mobility. Limitations in physical activity may influence health-related quality of life and independence, which could, in turn, be related to selfefficacy [39]. Self-efficacy has been associated with greater self-care and fewer missed dialysis appointments amongst ESRD patients and may mediate the impact of depression on adherence in other patient populations [40-43]. We noted higher rates of depression and pain among non-adherent dialysis patients. ESRD patients with co-morbid depression or pain are at higher risk of ED use, and pain has been cited as a potential risk factor for withdrawing from dialysis treatment [11, 38, 44]. However, depression may be under-recognized and under-treated in ESRD patients [45]. Dialysis patients should be longitudinally screened for both depression and pain, and managed appropriately.

As a measure of neighborhood and built environment, transportation is often cited as a powerful predictor for non-adherence. Accordingly, we found that nonadherent dialysis patients were far more likely to rely on public transportation, less likely to drive, and frequently reported that transportation issues led to missed HD treatments. Transportation barriers could be potentiated by the increased prevalence of pain and physical limitations among non-adherent patients. Although distance 
to dialysis may have impacted transport modality and adherence to treatment, we did not find a significant correlation. Prior studies have indicated an increased risk for missed treatments among patients using a transportation van or with longer drives to HD [11]. However, since we did not collect information regarding transit times, it was not clear if shorter transit times to appointments predicted adherence.

Education and economic stability (e.g., employment status, DCI) were not significantly associated with dialysis adherence. The latter is likely due to the fact that very few patients in both the adherent and the nonadherent groups were employed full-time. The majority of participants were receiving disability benefits or were retired. Nevertheless, $24 \%$ of cases reported that a systems issue related to healthcare access led to missed HD treatment. Further studies are needed to better understand the role of economic stability with dialysis adherence.

Although multi-site studies have shown a correlation between low health literacy and non-adherence, we did not detect a significant association [32, 38]. Similar focused, smaller studies have also failed to show a significant correlation between health literacy and preventable hospitalizations or ED visits [46]; as such, it is unclear whether health literacy itself impacts adherence, whether it serves as a surrogate for other $\mathrm{SDOH}$, or whether these variations are attributed to context-specific factors. Furthermore, since most studies examining risk factors for non-adherence have been conducted across multiple study sites, the aggregation of the data may have resulted in the loss of local context and variations in $\mathrm{SDOH}$. Similarly, we did not detect a significant association between satisfaction with care and non-adherence to dialysis. This suggests that trust towards the healthcare establishment is highly variable between communities, emphasizing the importance of local community context when examining the influence of $\mathrm{SDOH}$.

\section{Limitations}

Similar to other patient-centric pilot studies, we recognize that our primary limitation to generalization is our sample size. Despite the small sample size, however, our study offers a rich cross-section of data and provides a "portrait" of the non-adherent dialysis patient in our inner city major metropolitan setting, which may inform future studies and interventions. Our study population was predominantly African-American; while this may render our results applicable to similar metropolitan settings, they are not necessarily applicable to all settings or the US dialysis patient population at large. Our study did not attempt to capture all possible risk factors, such as tobacco use or marital status, but examined a representative sample of $\mathrm{SDOH}$. Certain variables which trended towards but did not achieve statistical significance, such as distance to dialysis, may impact adherence. Moreover, our small sample size prevented the analysis of any possible associations between $\mathrm{SDOH}$ and reasons given by patients for missing sessions. Additionally, since critically ill patients were excluded from our study, it is possible that their HD non-adherence was the result of a significant medical illness, and not necessarily related to social determinants. Respondents may have been subject to recall and self-selection bias.

\section{Conclusions}

Non-adherent dialysis patients who present to the ED require prolonged inpatient visits and use multiple resources while in the ED. The interactions and impacts of specific SDOH may vary by context, and further studies aimed at risk factor identification or intervention design should be locally-focused. This pilot study demonstrates the interdisciplinary collaborative potential between long-term care providers (nephrologists) and acute care providers (emergency medicine providers). This "across the continuum" approach may be key in identifying the most socially-vulnerable patients, evaluating the prevalence of unmet $\mathrm{SDOH}$ in such populations, optimizing adherence to treatment regimens, and influencing health-seeking behavior by designing comprehensive, context-specific interventions that can be conducted either in the outpatient setting or at point-of-care in the ED itself. Our findings suggest that an inter-professional approach, incorporating psychiatric services, social work, case management and pain management, may be most effective in addressing the complex, interrelated SDOH that contribute to these patterns of healthcare utilization.

\section{Abbreviations}

CDC: Centers for Disease Control; DCl: Distressed Communities Index

ED: Emergency department; EMR: Electronic medical record; ESRD: End-stage renal disease; HD: Hemodialysis; KQ-QOL: Kidney Disease Quality of Life; PHQ9: Patient Health Questionnaire-9; REALM-S: Rapid Estimate of Adult Literacy in Medicine Short Form; SDOH: Social determinants of health; WHO: World Health Organization

\section{Acknowledgements \\ $\mathrm{N} / \mathrm{A}$}

\section{Prior presentations}

Balhara KS, Fisher L, Ramos R, Jaar B. Missed Dialysis and Emergency

Department Visits: Assessing Risk Factors and Resource Utilization. Society for Academic Emergency Medicine. Indianapolis, Indiana. May 2018. Oral presentation.

\section{Authors' contributions}

KSB and BGJ developed the study concept and design, and acquired funding. KSB, LF, and NE acquired the data. KSB, LF, RGR, and BGJ analyzed and interpreted the data. RGR provided statistical expertise. KSB drafted the manuscript. All authors were responsible for critical revision of the manuscript for important intellectual content. All authors have read and approved the manuscript in its current state. 


\section{Authors' information}

This work represents the product of an interdisciplinary collaboration between nephrology and emergency medicine.

$\mathrm{KSB}$ is a junior faculty member in Emergency Medicine at the Johns Hopkins Hospital who has previously conducted qualitative studies on access to care amongst patients with end-stage renal disease, which have resulted in peerreviewed publications and presentations at society meetings. She has conducted this work in conjunction with and under the mentorship of BGJ, who is a senior nephrologist with epidemiology training, currently section editor for epidemiology and outcomes research for the journal.

KSB's unique perspective as an emergency physician with a research interest in healthcare access amongst dialysis patients and her previous collaborations with BGJ led to the development of the research question and interdisciplinary study protocol described $\mathrm{n}$ this study.

\section{Funding}

This work was funded by the National Kidney Foundation of Maryland's Norma E. Clauss Clinical Research Award. The funding body did not impact the design of the study or the collection, analysis, and interpretation of data or in writing the manuscript.

\section{Availability of data and materials}

The datasets used during the current study are available from the corresponding author on reasonable request.

\section{Ethics approval and consent to participate}

This study was approved by the institutional review boards at Johns Hopkins University School of Medicine and Good Samaritan Hospital. Written or verbal consent was obtained from all participants. Written consent was obtained from patients who were recruited in-person. Verbal consent using a standardized script was obtained from patients who were recruited on the phone after their ED visit, since in-person written consent would not have been possible. Both consent strategies (written and verbal) were approved by both institutional review boards.

\section{Consent for publication}

Not applicable.

\section{Competing interests}

Dr. Bernard Jaar is a member of the Editorial Board of BMC Nephrology. The authors declare that they have no additional competing interests.

\section{Author details}

${ }^{1}$ The Johns Hopkins University School of Medicine, Baltimore, MD, USA. ${ }^{2}$ University of the West Indies, Mona, Jamaica. ${ }^{3}$ West Penn Hospital, Pittsburgh, PA, USA. ${ }^{4}$ The University of Texas Health Science Center at San Antonio, San Antonio, TX, USA. ${ }^{5}$ The Johns Hopkins Bloomberg School of Public Health, Baltimore, MD, USA. ${ }^{6}$ The Welch Center for Prevention, Epidemiology, and Clinical Research, Baltimore, MD, USA. ${ }^{7}$ Nephrology Center of Maryland, Baltimore, MD, USA.

\section{Received: 20 August 2019 Accepted: 27 December 2019}

\section{Published online: 06 January 2020}

\section{References}

1. Marcozzi D, Carr B, Liferidge A, Baehr N, Browne B. Trends in the contribution of emergency departments to the provision of hospitalassociated health care in the USA. Int J Health Serv. 2018;48:267-88.

2. Rui P, Kang K. National Hospital Ambulatory Medical Care Survey: 2015 Emergency Department Summary Tables. http://www.cdc.gov/nchs/data/ ahcd/nhamcs_emergency/2015_ed_web_tables.pdf. Accessed 10 Jan 2019.

3. LaCalle E, Rabin E. Frequent users of emergency departments: the myths, the data, and the policy implications. Ann Emerg Med. 2010;56:42-8.

4. Doupe MB, Palatnick W, Day S, Chateau D, Soodeen RA, Burchill C, et al. Frequent users of emergency departments: developing standard definitions and defining prominent risk factors. Ann Emerg Med. 2012;60:24-32.

5. Pines J, Asplin BR, Kaji AH, Lowe RA, Magid DJ, Raven M, et al. Frequent users of emergency department services: gaps in knowledge and a proposed research agenda. Acad Emerg Med. 2011;18:e64-9.
6. Mandelberg JH, Kuhn RE, Kohn MA. Epidemiologic analysis of an urban, public emergency department's frequent users. Acad Emerg Med. 2000;7: 637-46.

7. United States Renal Data System. 2018 USRDS annual data report: Epidemiology of kidney disease in the United States. Bethesda: National Institutes of Health, National Institute of Diabetes and Digestive and Kidney Diseases; 2018.

8. Lovasik BP, Zhang R, Hockenberry JM, Schrager JD, Pastan SO, Mohan S, et al. Emergency department use and hospital admissions among patients end-stage renal disease in the United States. JAMA Intern Med. 2016;176: $1563-5$.

9. Komenda P, Tangri N, Klajncar E, Eng A, Di Nella M, Hiebert B, et al. Patterns of emergency department utilization by patients on chronic dialysis: a population-based study. PLoS One. 2018;13:e0195323.

10. Loran MJ, McErlean M, Eisele G, Raccio-Robak N, Verdile VP. The emergency department care of hemodialysis patients. Clin Nephrol. 2002;57:439-43.

11. Chan KE, Thadhani Rl, Maddux FW. Adherence barriers to chronic Dialysis in the United States. J Am Soc Nephrol. 2014;25:2642-8.

12. Saran R, Bragg-Gresham JL, Raynes HC, Goodkin DA, Keen ML, Van Dijk PC, et al. Nonadherence in hemodialysis: associations with mortality, hospitalization, and practice patterns in the DOPPS. Kidney Int. 2003;64:254-62.

13. Al Salmi I, Larkina M, Wang M, Subramanian L, Morgenstern H, Jacobson SH, et al. Missed hemodialysis treatments: international variation, predictors, and outcomes in the Dialysis outcomes and practice patterns study (DOPPS). Am J Kidney Dis. 2018;72:634-43.

14. Denhaerynck K, Manhaeve D, Dobbels F, Garzoni D, Nolte C, De Geest S. Prevalence and consequences of nonadherence to hemodialysis regimens. Am J Crit Care. 2007;16:222-35.

15. Hafez D, McMahon LF, Balogh L, Brinley FJ 3rd, Crump J, Ealovega M, et al. Ambulatory care-sensitive emergency visits among patients with medical home access. Am J Manag Care. 2018;1:e73-8.

16. Oster A, Bindman AB. Emergency department visits for ambulatory care sensitive conditions: insights into preventable hospitalizations. Med Care. 2003:41:198-207.

17. Freund T, Campbell SM, Geissler S, Kunz CU, Mahler C, Peters-Klimm F, et al. Strategies for reducing potentially avoidable hospitalizations for ambulatory care-sensitive conditions. Ann Fam Med. 2013;11:363-70.

18. Huang $Y$, Meyer $P$, Jin L. Neighborhood socioeconomic characteristics, healthcare spatial access, and emergency department visits for ambulatory care sensitive conditions for elderly. Prev Med Rep. 2018;12:101-5.

19. Golestaneh L, Bellin E, Neugarten J, Lo Y. Avoidable visits to the emergency department (ED) and their association with sex, age and race in a cohort of low socio-economic status patients on hemodialysis in the Bronx. PLoS One. 2018;13:e0202697.

20. Hall YN. Social determinants of health: addressing unmet needs in nephrology. Am J Kidney Dis. 2018;72:582-91.

21. Schroeder SA. Shattuck lecture. We can do better-improving the health of the American people. N Engl J Med. 2007;357:1221-8.

22. Vart P, Gansevoort RT, Crews DC, Reijneveld SA, Bultmann U. Mediators of the association between low socioeconomic status and chronic kidney disease in the United States. Am J Epidemiol. 2015;181:385-96.

23. Morton RL, Schlackow I, Staplin N, Gray A, Cass A, Haynes R, et al. Impact of educational attainment on health outcomes in moderate to severe CKD. Am J Kidney Dis. 2016;67:31-9.

24. Anderson ES, Lippert S, Newberry J, Bernstein E, Alter HJ, Wang NE. Addressing social determinants of health from the emergency department through social emergency medicine. West J Emerg Med. 2016;17:487-9.

25. Malecha PW, Williams JH, Kunzler NM, Goldfrank LR, Alter HJ, Doran KM. Material needs of emergency department patients: a systematic review. Acad Emerg Med. 2018;25:330-59.

26. Hemmelgarn BR, Manns BJ, Quan H, Ghali WA. Adapting the Charlson comorbidity index for use in patients with ESRD. Am J Kid Dis. 2003;42:125-32.

27. Rao S, Carter WB, Mapes DL, Kallich JD, Kamberg CJ, Spritzer KL, et al. Development of subscales from the symptom/problems and effects of kidney-disease items in the kidney disease quality of life (KDQOL $\left.{ }^{\mathrm{TM}}\right)$ instrument. Clin Ther. 2002;22:1099-111.

28. Watnick S, Wang PL, Demadura T, Ganzini L. Validation of 2 depression screening tools in dialysis patients. Am J Kidney Dis. 2005:46:919-24.

29. Office of Disease Prevention and Health Promotion. Social Determinants of Health. In: Healthy People; 2020. https://www.healthypeople.gov/2020/ topics-objectives/topic/social-determinants-of-health. Accessed 1 Mar 2016. 
30. Economic Innovation Group. Distressed Communities Index: Methodology. https://eig.org/dci/methodology. Accessed 1 July 2017.

31. Davis TC, Long SW, Jackson RH, Mayeaux EJ, George RB, Murphy PW, et al. Rapid estimate of adult literacy in medicine: a shortened screening instrument. Fam Med. 1993;25:391-5.

32. Green JA, Mor MK, Shields AM, Sevick MA, Arnold RM, Palevsky PM, et al. Associations of health literacy with dialysis adherence and health resource utilization in patients receiving maintenance hemodialysis. Am J Kidney Dis. 2013;62:73-80

33. Rubin HR, Jenckes M, Fink NE, Meyer K, Wu AW, Bass EB, et al. Patient's view of dialysis care: development of a taxonomy and rating of importance in different aspects of care. CHOICE study. Choices for healthy outcomes in caring for ESRD. Am J Kidney Dis. 1997;30:793-801.

34. Wu AW, Fink NE, Cagney KA, Bass EB, Rubin HR, Meyer KB, et al. Developing a health-related quality-of-life measure for end-stage renal disease: the CHOICE healthy experience questionnaire. Am J Kidney Dis. 2001;37:11-21.

35. Harris AP, Taylor R, Thielke R, Payne J, Gonzalez N, Conde JG. Research electronic data capture (REDCap) - a metadata-driven methodology and workflow process for providing translational research informatics support. J Biomed Inform. 2009;42:377-81.

36. Gilboy N, Tanabe T, Travers D, et al. Emergency Severity Index (ESI): A Triage Tool for Emergency Department Care, Version 4. Implementation Handbook 2012 Edition. Rockville: Agency for Healthcare Research and Quality; 2011.

37. Ronksley PE, Tonelli M, Manns BJ, Weaver RG, Thomas CM, McRae JM, et al. Emergency department use among patients with CKD: a population-based analysis. Clin J Am Soc Nephrol. 2017:12:304-14.

38. Tohme F, Mor MK, Pena-Polanco J, Green JA, Fine MJ, Palevsky PM, et al. Predictors and outcomes of non-adherence in patients receiving maintenance hemodialysis. Int Urol Nephrol. 2017;49:1471-9.

39. Kim JY, Kim B, Park KS, Choi JY, Seo JJ, Park SH, et al. Health-related quality of life with KDQOL-36 and its association with self-efficacy and treatment satisfaction in Korean dialysis patients. Qual Life Res. 2013;22:753-8.

40. Lin CC, Tsai FM, Lin HS, Hwang SJ, Chen HC. Effects of a self-management program on patients with early-stage chronic kidney disease: a pilot study. Appl Nurs Res. 2013;26:151-6.

41. Kauric-Klein Z, Peters RM, Yarandi HN. Self-efficacy and blood pressure selfcare behaviors in patients on chronic hemodialysis. West J Nurs Res. 2017; 39:886-905

42. Zrinyi M, Juhasz M, Balla J, Katona E, Bent T, Kakuk G, et al. Dietary selfefficacy: determinant of compliance behaviours and biochemical outcomes in haemodialysis patients. Nephrol Dial Transplant. 2003;18:1869-73.

43. Maeda U, Shen BJ, Schwarz ER, Farrell KA, Mallon S. Self-efficacy mediates the associations of social support and depression with treatment adherence in heart failure patients. Int J Behav Med. 2013:20:88-96.

44. Davison SN, Jhangri GS. The impact of chronic pain on depression, sleep, and the desire to withdraw from dialysis in hemodialysis patients. J Pain Symptom Manag. 2005;30:465-73.

45. Watnick S, Kirwin P, Mahnensmith R, Concato J. The prevalence and treatment of depression among patients starting dialysis. Am J Kidney Dis. 2003:41:105-10.

46. Levine R, Javalkar K, Nazareth M, Faldowski RA, de Ferris MD, Cohen S, et al. Disparities in health literacy and healthcare utilization among adolescents and young adults with chronic or end-stage kidney disease. J Pediatr Nurs. 2018;38:57-61

\section{Publisher's Note}

Springer Nature remains neutral with regard to jurisdictional claims in published maps and institutional affiliations.

\section{Ready to submit your research? Choose BMC and benefit from:}

- fast, convenient online submission

- thorough peer review by experienced researchers in your field

- rapid publication on acceptance

- support for research data, including large and complex data types

- gold Open Access which fosters wider collaboration and increased citations

- maximum visibility for your research: over $100 \mathrm{M}$ website views per year

At $\mathrm{BMC}$, research is always in progress.

Learn more biomedcentral.com/submissions 